Portland State University

PDXScholar

\title{
A Comparative Study of Phonemic Segmentation Skills in First Grade Children with Normal, Disordered, and Slow Expressive Language Development
}

David J. Andrews

Portland State University

Follow this and additional works at: https://pdxscholar.library.pdx.edu/open_access_etds

Part of the Speech and Rhetorical Studies Commons

Let us know how access to this document benefits you.

\section{Recommended Citation}

Andrews, David J., "A Comparative Study of Phonemic Segmentation Skills in First Grade Children with Normal, Disordered, and Slow Expressive Language Development" (1994). Dissertations and Theses. Paper 4750.

https://doi.org/10.15760/etd.6634

This Thesis is brought to you for free and open access. It has been accepted for inclusion in Dissertations and Theses by an authorized administrator of PDXScholar. Please contact us if we can make this document more accessible: pdxscholar@pdx.edu. 


\section{THESIS APPROVAL}

The abstract and thesis of David J. Andrews for the Master of Science in Speech Communication: Speech and Hearing Sciences were presented May 3, 1994, and accepted by the thesis committee and the department.

COMMITTEE APPROVALS:

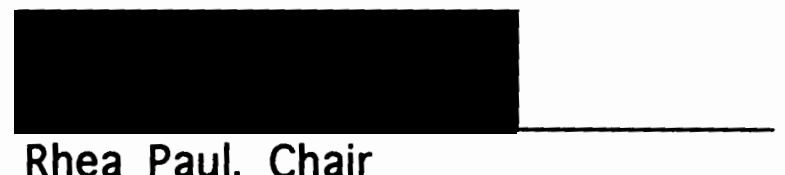

Rhea Paul, Chair

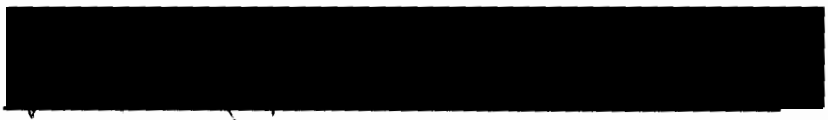

Mary Gordon-Brannan

DEPARTMENT APPROVAL:

Stephen A. Kosokoff, Chair Department of Speech Communication

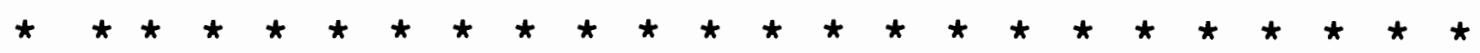

ACCEPTED FOR PORTLAND STATE UNIVERSITY BY THE LIBRARY

by

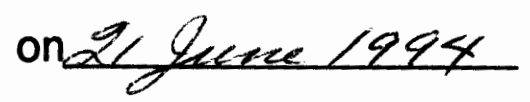




\section{ABSTRACT}

An abstract of the thesis of David J. Andrews for the Master of Science in Speech Communication: Speech and Hearing Sciences presented May 3, 1994.

Title: A Comparative Study of Phonemic Segmentation Skills in First Grade Children With Normal, Disordered, and Slow Expressive Language Development.

Children with slow expressive language development often catch up to their normally developing peers in expressive language, but may still exhibit difficulties with metalinguistic skills. Research shows that children who have difficulty with phonemic awareness also have difficulty with reading, which is important for success in school. Speech-language pathologists assist children who have difficulty with expressive oral language and facilitate language development in children who have difficulties with learning metalinguistic skills, such as phonemic awareness.

The purpose of the present study was to compare the phoneme segmentation skills in three groups of children: (a) children with a history of oral expressive language delay (HELD) $(\underline{n}=22)$ who were identified as toddlers with slow developing expressive language, but caught up to their normally developing peers by first grade; (b) 
children identified as toddlers with slow developing oral expressive language and by first grade still maintained the expressive language delays (ELD) $(n=7)$; and (c) children who were identified at age two as developing normal oral expressive language and maintained normal oral expressive language development $(N L)(n=23)$ in first grade.

The children participated in a phonological segmentation test. The study answered four questions: Is there a significant difference among the three groups of children in the number of correct responses on a phonological segmentation test at (1) the one phoneme level, (2) the two phoneme level, (3) the three phoneme level, and (4) the total number of correct responses.

Utilizing an ANOVA test, a significant difference was found among the groups at the two phoneme level, with a trend toward a significant difference at the one phoneme level. Other significant differences were not found. The difference at the two phoneme level was between the ELD group and the normal group, as well as between the ELD group and the HELD group. 
A COMPARATIVE STUDY OF PHONEMIC SEGMENTATION SKILLS IN FIRST GRADE CHILDREN WITH NORMAL, DISORDERED, AND SLOW EXPRESSIVE LANGUAGE DEVELOPMENT

\author{
by \\ DAVID J. ANDREWS
}

A thesis submitted in partial fulfillment of the requirements for the degree of

\author{
MASTER OF SCIENCE \\ in \\ SPEECH COMMUNICATION: \\ SPEECH AND HEARING SCIENCES
}

Portland State University

1994 


\section{ACKNOWLEDGEMENTS}

Many thanks go to many people for helping me with this project. I would like to thank Dr. Rhea Paul for her continued support throughout my studies and for the use of her subjects. This project was completed in a timely manner thanks to Dr. Paul's encouragement.

I would not have completed this project, nor the masters degree in the Speech/Language program without the continued, everyday support of my wife Sarah. Thank you Sarah, for locking me upstairs. Gratitude also goes to my friends, especially Susanne and Christopher, also provided a lift when I needed it. I need to say a word about my mother and father, who guided me through life choices and encouraged me over the phone every weekend from Illinois (back East!!!). Without their role-models, I would not be where I am today. They both taught me about life in general, speechlanguage pathology, and the role of interpersonal and family relationships in this field.

Thanks also to Dr. Mary Gordon-Brannan, Carol Mack, and to all the members of the Speech and Hearing Sciences staff and faculty. Including Mary T. Withers, for her encouragement from the first day I set foot into the basement of Neuberger hall. 
TABLE OF CONTENTS

PAGE

ACKNOWLEDGEMENTS ................. ii

LIST OF TABLES . . . . . . . . . . . . . . . . . v

CHAPTER

I INTRODUCTION AND STATEMENT OF PURPOSE . . . . . 1

Introduction ............... . 1

Statement of Purpose . . . . . . . . . . 3

Definition of Terms . . . . . . . . . . . 5

II REVIEW OF THE LITERATURE . . . . . . . . . . . . 7

Phonology and Metaphonology. . . . . . . . . . 7

The Development of Phonological Awareness . . . 9

Differences Between the Oral and Written Form of Language and the Importance of Phonological

Awareness . . . . . . . . . . . . 12

Relation of Phonological Awareness to Reading . . 14

Different Phonological Assessment Techniques . . 19

Results of Training Phonological Awareness in

Beginning Readers... . . . . . . 20

Clinical Ideas for Teaching Phonological

Awareness ............. 23

Summary . . . . . . . . . . . . . . . 24

III METHODS AND PROCEDURES . . . . . . . . . . . . 25

Subjects . . . . . . . . . . . . . 25 
Subject Recruitment

Subject Placement at Intake

Subject Placement at Follow-up

Procedures . . . . . . . . . . . . . 28

Analysis............... . 33

IV RESULTS AND DISCUSSION . . . . . . . . . . 34

Results ............... . 34

Discussion .. . . . . . . . . . . . 38

$\checkmark$ SUMMARY AND IMPLICATIONS . . . . . . . . . . 42

Summary . . . . . . . . . . . . . . 42

Implications .............. . . 44

Research

Clinical

REFERENCES . . . . . . . . . . . . . . . . . . . . . . . 48 APPENDIXES

A LANGUAGE DEVELOPMENT SURVEY . . . . . . . . . . . 53

B DEVELOPMENTAL SCORING ANALYSIS SHEET AND PERCENTILE CHART . . . . . . . . . . . . . . . . . 55

C PHONOLOGICAL AWARENESS TEST . . . . . . . . . . 58

D HUMAN SUBJECTS RESEARCH WAIVER . . . . . . . 62

E RAW DATA OF DSS AND PHONOLOGICAL AWARENESS TEST. 64 


\section{LIST OF TABLES}

TABLE

PAGE

1 Group Demographic Information at Intake . . . . . . . 27

2 Group Demographic Information and DSS Score at Follow-Up................ . . 29

3 Mean, Standard Deviation, and Range of Each Dependent Measure for Each of the Three Diagnostic Groups . . . . 36

4 Results of the One-Way Analysis of Variance (ANOVA) - 37

5 Results of the Tukey Multiple Comparisons Test Between Groups at the Two Phoneme Level . . . . . . . . . 37 


\title{
CHAPTER I
}

\section{INTRODUCTION AND STATEMENT OF PURPOSE}

\author{
Introduction
}

One of the many roles of the speech-language pathologist is to facilitate language and phonological development in toddlers and preschool children who experience difficulties with expressive oral language. Speech-language pathologists work with children to facilitate effective communication skills, to improve social development, to build self-esteem, and to support the family in their efforts and concerns. One of the primary reasons speech-language pathologists facilitate expressive oral language is to enable children to build the language base needed to succeed in school. Speech-language pathologists often wonder if intervention is necessary for toddlers who are slow to develop expressive language. Some children who are slow to develop expressive language "catch up" to their normally developing peers, while other children who are slow to develop expressive language will have expressive oral language difficulties through age four and continue to exhibit expressive language deficits in kindergarten (Paul, 1993).

When children do "catch up" to their peers in expressive oral language, it is presently unknown if the underlying language deficit 
will maintain itself in the first grade, when children are developing higher-order language operations, such as metalinguistic awareness. Metalinguistic awareness involves the conscious awareness of language and one's ability to think about language as a tool for more than just expressing and receiving a message in context. Children who develop metalinguistic awareness are able to manipulate and reflect on the rules of the language. Research has revealed that this skill is essential for school achievement (Catts, 1989).

One aspect of metalinguistic awareness is phonological awareness. Phonological awareness is an awareness of the phonological units in spoken language, such as syllables, phonemes, and phones. Phonemic awareness is one specific aspect of phonological awareness, which is knowing that words can be segmented into sounds or phonemes and that these phonemes are represented by arbitrary symbols that can be manipulated in different ways to form words (Treiman, 1991).

The literature presently supports a strong correlation between phonemic awareness skills and reading and school achievement in children with normal language development. However, the literature contains little information about the development of phonemic awareness in children who have a history of slow expressive language development. 
Statement of Purpose

The purpose of this study is to compare the phonological segmentation skills in three groups of children: (a) children with a history of oral expressive language delay (HELD) who were identified as toddlers with slow developing expressive language, but caught up to their normally developing peers by first grade; (b) children identified as toddlers with slow developing oral expressive language and by first grade still maintained the expressive language delays (ELD); and (c) children who were identified at age two as developing normal oral expressive language and maintained normal oral expressive language development (NL) in first grade. The questions addressed by this study include:

1. Is there a significant difference among the three groups of children in the number of correct responses on a phonological segmentation test at the one-phoneme level?

2. Is there a significant difference among the three groups of children in the number of correct responses on a phonological segmentation test at the two-phoneme level?

3. Is there a significant difference among the three groups of children in the number of correct responses on a phonological segmentation test at the three-phoneme level?

4. Is there a significant difference among the three groups of children in the total number of correct responses on a phonological segmentation test? 
This study tests four research hypotheses:

1. There will be a significant difference among the three groups of children in the number of correct responses on a phonological segmentation task at the one-phoneme level.

2. There will be a significant difference among the three groups of children in the number of correct responses on a phonological segmentation task at the two-phoneme level.

3. There will be a significant difference among the three groups of children in the number of correct responses on a phonological segmentation task at the three-phoneme level.

4. There will be a significant difference among the three groups of children in the number of total correct responses on a phonological segmentation task.

The corresponding null hypotheses are:

1. There will not be a significant difference among the three groups of children in the number of correct responses on a phonological segmentation task at the one-phoneme level.

2. There will not be a significant difference among the three groups of children in the number of correct responses on a phonological segmentation task at the two-phoneme level.

3. There will not be a significant difference among the three groups of children in the number of correct responses on a phonological segmentation task at the three-phoneme level.

4. There will not be a significant difference among the three groups of children in the total number of correct responses on a phonological segmentation task. 
Definition of Terms

Developmental Sentence Scoring (DSS): A syntactical analysis of children's utterances developed by Lee (1974).

Expressive Language Delay (ELD): Children identified as toddlers with slow developing oral expressive language and by first grade still maintained the expressive language delays.

History of expressive language delay (HELD): Children who were identified as toddlers with slow developing expressive language, but caught up to their normally developing peers by first grade.

Normally developing language: Children who were identified as toddlers as developing normal oral expressive language and maintained normal oral expressive language development.

Metalinguistic awareness: Conscious awareness of language and one's ability to think about and reflect on the rules of language (Catts, 1989).

Metaphonology: The explicit knowledge of the rules governing a phonological system, or sound structure of a language.

Phonemic awareness: One specific aspect of phonological awareness, which is knowing that words can be segmented into sounds or phonemes and that these phonemes are represented by arbitrary symbols that can be manipulated in different ways to form words.

Phonemic blending: The task of listening to sounds presented separately, and blending them into a word. 
Phonemic segmentation: The task of segmenting a word into its component phonemes.

Phonological awareness: An awareness of the phonological units in spoken language, such as syllables, intrasylabic units, and phonemes.

Phonology: The aspect of language concerned with the rules governing the structure, distribution, and sequencing of speech sounds in a language.

Sound Categorization: The task of categorizing words by listening to phonemic similarities and differences at various positions in the word.

Word Discrimination: Knowing that two words sound different, and mean something different, without being aware of the specific phonological components of the words. 
CHAPTER ॥

\section{REVIEW OF THE LITERATURE}

Phonology and Metaphonology

Phonology is the aspect of language involved with phonemes, or individual speech sounds, that coalesce to make words. The developing speaker is biologically programmed to learn language, and naturally learns the phonological distribution and sequence rules of the language (Vellutino, 1991). An example of an English phonological distribution rule is that speakers may end a word with /ts/ but can not begin a word with /ts/. An example of an English language sequence rule is that $/ \mathrm{tr} /$ as in the word truck is a possible sequence within the same syllable, but $/ \mathrm{tl} /$ is not. In an alphabetic language such as English, literate adults know that written alphabetic letters within syllables and words represent phonemes, and know that these phonemes can be manipulated and combined to create different words (Read, Yun-Fei, Hong-Yin, Bao-Qing, 1987).

When people communicate with one another, they speak in sentences, but sentences divide into phrases, words, syllables, and finally into individual speech sounds. Yopp (1992) pointed out that phonemes are not an obvious part of the English language, they are very abstract. In everyday conversation, communicators do not 
analyze the phonemes used by their conversational partners, rather, they listen only for meaning. There are no definable boundaries between spoken phonemes, and speakers often assimilate phonemes together, such as the $/ t /$ and $/ d /$ in the word hotdog. Speakers make subtle changes in their production of sounds depending on the phonological content. The way they produce the $/ /$ in the word bowl is different from the $/ / /$ in the word leaf, but the written $\underline{L}$ is consistent.

People who understand the written form of language have metalinguistic awareness. Metalinguistic awareness is the ability to talk about language and manipulate language for purposes other than comprehending meaning. One aspect of metalinguistic awareness is metaphonological, or phonological awareness. The knowledge that words segment into sounds and that these sounds are represented by abstract symbols that can be manipulated to form different words is one aspect of this awareness, referred to as phonemic awareness. Phonological awareness also includes an awareness about any of the phonological units, such as knowing that words can also be segmented and manipulated at the syllable level. When analyzing written phonemes, readers must have the metalinguistic skill of treating these symbols as objects, and must know that alphabetic writing represents meaningful language that can be spoken (Trieman, 1991).

One must dissociate the skills involved in being aware of phonemes from the ability to discriminate phonemes. Eimas (1985) researched the ability of infants to discriminate between sounds, 
such as / $\mathrm{pa} /$ and $/ \mathrm{ba} /$. This ability to discriminate appears to be a biologically programmed skill, whereas the ability to know that the word pot starts with the $/ p /$ sound is a development of the phonological awareness aspect of English.

Another example of the difference between discrimination and phonemic awareness is the following scenario discussed by Wallach, Wallach, Dozier, and Kaplan, (1977). For example, a picture of mail and a picture of a whale is presented to the child. The child listens to the examiner say mail or whale, then the examiner asks the child to point to the named picture. This is an example of discrimination. The child would demonstrate phonemic awareness if the examiner said "point to the picture that begins with $/ \mathrm{m} /$ " and the child pointed to the picture of mail. Wallach et al. (1977) revealed that children who had difficulty with phonemic awareness did not have difficulty with auditory discrimination.

The Development of Phonological Awareness

Phonological awareness is a learned, later-developing skill. The knowledge of the written phonological structure is not part of the biologically programmed ability in humans to learn language. Several studies have shown that metalinguistic skills associated with reading and writing, including phonological awareness, are not spontaneously attained during language development. It is a skill that must be taught. Studies show that not all speakers and listeners become readers. Adults who do not read alphabetic 
orthography have trouble manipulating phonemes in phonological awareness tasks. This indicates that the ability to segment phonemes into sounds is a learned process that relates to reading (Mann, 1987).

Although children may not be able to succeed in structured phonological awareness tasks until they are 5 or 6 years old, many children begin to develop prephonological awareness skills at the age of 2 years, when they begin to repair phonological errors and spontaneously play with words in the language (VanKleeck \& Schuele, 1987).

VanKleeck and Schuele (1987) summarized examples of data collected by various researchers on spontaneous phonological repairs, nonsense sound play, alliteration, and word play, that are emerging demonstrations of phonological awareness. Children make phonological repairs when they are first acquiring new words in an attempt to make themselves better understood. These repairs may not always evolve into correct pronunciations of the target word, but the attempts show that children are aware of language and its usage. Nonsense sound play includes children playing with a single word in a nonsense way, such as a child who is $21 / 2$ years saying tri ya ya ya yangle. Word alliteration is manipulating the sounds in words, as in a 3 year-old saying Deanut dutter dandwich, and I want reanut rutter randwich, rease. Children add endings to words, play with or practice the pronunciation of a word, and rhyme words, such as David is a shavid. Children have also been shown to comment on and/or attract attention to pronunciation, segment words into 
phonemes, as well as describe to a listener what sounds words start with, such as saying to an adult Mama starts with $/ \mathrm{m} /$. This is a true example of phonological awareness.

The need to be aware of phonemes does not generally occur before reading because there is not an urgent need for oral communicators, such as younger children in the developing language phase, to know about phonological awareness. However, phonological awareness in the developing language period may be important for success in the school years (Gombert, 1992).

Liberman, Shankweiler, Fischer, and Carter (1974) reported that a developmental pattern exists when children are learning about phonemes. The children in their study showed an awareness of syllable segmentation prior to phonemic segmentation. Half of the children in their study could segment words into syllables by age 4 . By age $6,90 \%$ of the children performed well on the syllable segmentation task, and $70 \%$ of the children could segment words into sounds.

In another landmark study, found that phonological awareness has a general developmental pattern. They found the first stages of this development began when children are 3 . The examiner asked the children to "tell me a little bit of (phrase)." They found that segmenting sentences into words and words into syllables were easier for the children then segmenting the syllable into one or two phonemic sounds. (Saying "a little bit of pete" was correct if the child said /pi/). Three-year-olds segmented sentences into words and syllables for a mean of 3.42 out of the eight words, but they did 
poorly on segmenting syllables into phonemes. The 5- and 6-yearold children segmented sentences and words easily.

Differences Between the Oral and Written Form of Language and the Importance of Phonological Awareness

Although there are many similarities between oral and written language, there are also differences. An alphabetic cipher is not merely the written form of oral language. Blachman (1989) pointed out that when speaking, speakers coarticulate and blend consonants with vowels. People communicate messages as one acoustic unit, but when writing the word, they isolate each sound. When the beginning reader is required to read the word dad, the child must know that each letter represents a phoneme and the three individual sounds synthesize to form the word. Due to the abstraction of the isolated phonemes, becoming aware of the word at the phoneme level is a difficult task, but a necessary one for the beginning reader (Ball \& Blachman, 1988).

Reading, as with speaking, involves some of the same comprehension processes, such as discrimination and identification. To identify a written word correctly, readers must be able to associate sounds with letters. Letters are arbitrary symbols of the sounds, and the reader must understand the phoneme/grapheme correspondence. In speech, it is a simple process of discriminating between phonemic differences, such as $/ b /$ and $/ d /$, and then mapping the word for meaning, such as the difference between bad 
and $\underline{\text { dad. }}$. When reading, however, one must know that the written $\underline{b}$ means a spoken /b/, which is a higher level cognitive process (Kamhi $\&$ Catts, 1989).

When people listen to oral language, individuals map meaning by recognizing the spoken word through phonological representation. This representation occurs either through the word lexicon or by cluster lexicon. The word lexicon is the listener's understanding of word meaning, such as the meaning for dad. The cluster lexicon is the listener's knowledge of a group of words that have meaning, but are spoken as one unit, such as lt's a (Kamhi \& Catts, 1989).

The process of written word recognition has been debated greatly. There are two modes of possible written word recognition. First, is the direct, or whole word approach, in which a beginning reader makes a direct match in the lexicon with the whole word. The second way of representation is the indirect approach, in which beginning readers use their understanding of the phoneme-grapheme correspondence to match the word to its phonetic counterpart. The reader then blends the sounds and maps a meaning from the available lexicon. Beginning readers must use the indirect approach when looking at a word that is familiar part of their oral language base, but unfamiliar to them in written form. This method also helps the beginning reader understand the letter sequence rules (such as /th/) that apply in written English and other orthographic, alphabetic languages. One must be aware or have knowledge of the phonological aspects of speech and be able to realize associations between letters and phonemes to learn how to read. The indirect approach to 
reading enhances the direct approach, which is utilized by advanced readers (Kamhi \& Catts, 1989).

Vellutino (1991) argued that learning to speak depends upon "biologically specialized mechanisms that encode units of language with universally prescribed strategies that require no explicit tuition for their implementation" (p. 439). When learning to read the alphabetic system, one must be able to decode the abstractness of the individual sounds within spoken words. Phonemic awareness is necessary in order for the beginning reader to read the word and map the alphabetic symbols to the sound that it represents (Vellutino, 1991).

Relation of Phonological Awareness to Reading

Blachman (1989) stated that longitudinal studies of phonological awareness skills in kindergarten or first grade students are good predictors of future reading ability. Wagner (1986) also reported on longitudinal correlation studies between the relationship of phonological awareness and the acquisition of reading. He stated that studies show a causual relationship between phonological awareness and the acquisition of reading.

School age children who have difficulty reading often have phonological processing deficits. That is, they have difficulty with linguistic operations that use information about phonological sound structure. One of the key components of phonological processing is 
the awareness that individual sounds, or phonemic units, make up words (Catts, 1989).

To determine what kinds of phonological awareness assessments best predict reading ability, Stanovich, Cunningham, and Cramer (1984) administered ten different types of phonological awareness tasks to kindergarten children. They followed up 1 year later, after the children had finished first grade, with a measure of reading ability. Rhyming tasks proved to be easy, and had low correlation with reading ability. Other tasks directly related to reading ability included stripping the initial consonant of a word, supplying the initial consonant after listening to the word again, choosing among words with similar initial and/or final consonants, choosing among three words that had a different initial and/or final consonant, and choosing a different initial consonant when presented with four words. They concluded that any of these tasks are good predictors of reading ability in the first grade.

Mann and Liberman (1984) found a developmental pattern to syllable counting and found a correlation between syllable-counting and verbal short-term memory. On the basis of previous studies (Liberman et al., 1974) and the results of their study, they concluded that the ability to count syllables is a good predictor of reading.

Bradley and Bryant (1985) designed a longitudinal study that included 403 children ( 35 drop outs, final $\underline{N}=368$ ). They correlated phonological awareness and reading skills by testing the children on "finding the odd sound out" and correlating the scores to later reading ability. When orally presented with three or four words 
(three words to the four-year-olds, $\underline{n}=104$ and four words to the five-year-olds, $\underline{n}=264$ ) the children chose the word which contained the odd sound. The word with the odd sound out did not have a sound in common to the other words in either the initial, middle, or final position. They assessed memory and vocabulary in subsequent tests on the same words used in the task. They found that the rhyming tasks, in which the odd sound was the middle and last sound, were easier than the alliteration task, in which the odd sound was the first sound. A multiple regression analysis showed a significant correlation between sound categorization skills and reading 3 years later using the Neale analysis of reading, and the Schonell test of reading.

Juel, Griffith, and Gough (1986) also carried out a longitudinal study focusing on children in their early reading years (first and second graders). They found that when other variables were controlled, phonemic awareness skills, such as segmentation, blending, first/last sound deletion, and first/last sound substitution, significantly effected the children's first-grade yearend performance in word recognition and reading comprehension. Results also showed that poor oral language skills contributed to poor phonological awareness skills. They concluded that children with poor phonemic awareness skills are disadvantaged in learning to read and write, and suggested that oral phonemic awareness should precede reading instruction.

Catts (1986) studied the relationship of reading disorders and phonological deficits in children's production of multi-syllabic 
words. He showed that 12 to 15 -year-old students with reading disabilities made significantly more errors on oral sound production tasks, which included naming a phonetically complex picture, repeating multisyllabic words and repeating phrases. These deficits in speech production highly correlated with performance on the word attack subtest of the Woodcock Reading Mastery Test, in which the subjects must read phonemically plausible nonsense words aloud, consequently creating a measure of the grapheme-phoneme correspondence. He concluded that students who are reading disabled have more difficulty with phonological analysis than students with normal reading abilities. The difficulty with phonological analysis effected reading and oral language ability.

Vellutino and Scanlon (1987) assessed nonreading kindergartners with the Gilmore Oral Reading Test (Gilmore \& Gilmore, 1968) which has phonological segmentation and other phonological awareness subtests. They then readministered the tests to the children after first grade. Holding word recognition constant, they found a correlation between the phonemic segmentation task and oral reading. Their results also indicated that word identification, phonetic decoding, and phonemic segmentation are related skills.

Webster and Plante (1992) compared performance between a group of 6 to 8-year-old children with phonological process deficits, to their peers who had an absence of phonological errors in their speech, on a phonological segmentation task. The group of children who had phonological process deficits were less intelligible than 
their peers. The children were matched for chronological age, education experience, and nonverbal IQ. The phonological segmentation tasks administered were sentences-to-words, wordsto-syllables, and words-to-sounds, which included five 2-sound syllables, seven 3-sound syllables, and four 4-sound syllables. They found significant differences between the two groups in the wordsto-sounds segmentation task, which indicated that phonological segmentation ability is associated with speech intelligibility. They also found that a word recognition task, in which the children responded by choosing one of three written words that best correlated with a picture, highly correlated to word-phoneme segmentation. They concluded that phonemic segmentation is related to reading and that being able to segment phonemes partially depends on linguistic ability.

Fox and Routh (1980) also researched phonemic abilities in children with reading disorders. They showed that children with severe reading disabilities scored significantly lower when compared to their peers on phonemic segmentation tasks. Average readers and the children with mild reading difficulty had nearly perfect scores. The mean score was 43 for the group of girls and 40.4 for the group of boys. The group of boys with disordered reading scored a mean of 1.6 , and the group of girls with reading disorders had a mean score of 2.0. The segmenting task was similar to their 1975 study (e.g., say a little bit of the word; /pi/ for Pete was considered correct). 
Although some reading specialists are still arguing for the whole-word, direct approach to reading, the evidence above shows that phonological awareness is highly related to beginning reading. The debate has now shifted in focus to the question of whether phonological awareness is causal to reading or whether it is reciprocal with reading (Wagner \& Torgesen, 1987). Perfetti, Beck, Bell, and Hughes (1987) agreed that phonemic awareness is important for beginning reading, but they also showed that the more reading the beginner does, the better their phonemic awareness becomes.

\section{Different Phonological Assessment Techniques}

When assessing phonological awareness skills and its relationship to reading, it is important to be sure that the tool is testing the skills it is intended to test (Chabon \& Prelock, 1987). Bruck and Trieman (1990) pointed out that there are a variety of ways to assess phonological awareness including: rhyming, phoneme segmentation, matching tasks, phoneme substitution tasks, blending tasks, and phoneme counting tasks. They found that children had more difficulties segmenting consonant clusters than singleton consonants.

Chabon and Prelock (1987) believe that familiarity, elements involved, and the length of the stimulus make a difference as to whether the child will respond appropriately to phonological awareness tasks. Furthermore, the child's ability to comprehend the 
directions of the task is an important aspect. They believe that researchers and examiners must evaluate fully any instrument devised for assessing phonemic awareness, so that they are sure to obtain accurate results.

Spector (1992) discussed the practical use of dynamic assessment of phonemic awareness. Dynamic assessment is based on Vygotsky's zone of proximal development, which is the developmental distance between failure on a given task when working independently, and achieving success on the task with minimal assistance and guidance. Spector showed that dynamic assessment of phonemic awareness, in which the children were given supportive prompts and cues, more accurately predicted future reading progress than non-dynamic assessment.

Results of Training Phonological Awareness in Beginning Readers

Studies have shown that training children in phonological awareness assists them in the development of reading (Ball \& Blachman, 1988). Bradley and Bryant $(1983,1985)$ discussed the advantages of training sound categorization skills to children by using letters of the alphabet and colored pictures of familiar objects. They taught skills such as analyzing initial sounds while looking at pictures. For example, hen and hat both start with the letter $\underline{h}$ and sound like $/ \mathrm{h} /$. The researchers taught one group of children (group I) these skills. The researchers also taught another group of children (group II) these skills, but included plastic letters 
that represented the common sounds being discussed in the training. Using the same pictures, the researchers taught Group III conceptual categories, such as categorizing animals into farm animals or household pets, rather than sound manipulation. Group IV received no training at all from the examiners over the two-year period. Prior to the training, all the children scored two standard deviations below the mean on sound categorization, and none of the children could read. On the reading and spelling posttests, groups I and II performed better than the children who were not taught to analyze the sounds of English. The second group scored significantly better than groups III and IV and furthermore, group II, the group that was taught with the plastic letters, did better on the post-tests that group I.

Torgesen, Morgan, and Davis (1992) trained kindergarten children, with normal phonological skills, for 2 months on blending skills, such as /k-a-t/ (asking the child to say the word, after presenting the sounds separately), and analysis or segmenting skills, such as /kat/. "How many sounds are in the word." One group trained with both methods, and the other group trained in blending tasks only. They also had a control group who received no training in specific tasks, but were exposed to meaning-oriented, languageexperience activities. They found that the children who trained with both tasks did better on post-tests of blending and segmenting. The children who learned only blending skills did poorly on the analysis task but better on the blending task. The control group made the least amount of gains between the pre- and post-tests. The 
researchers concluded that awareness training in both types of tasks is best for overall improvement in phonological awareness. This study also showed that the children who trained with both segmentation and blending achieved better scores when post-tested for reading new words. They were able to read these new words significantly faster than the blending only group and were far superior to the control group.

Ball and Blachman (1988) discussed the success of reading readiness intervention with kindergartners through phoneme segmentation training. Children were assigned to the following three groups: (a) phoneme awareness training group $(\underline{n}=29),(b)$ language activities group ( $\underline{n}=30)$, and (c) no intervention group $(\underline{n}=30)$. Similarities across the groups included pretest skills on a one- two- and three-phoneme segmentation test (the test used in this present study), a raw score of three or less on the Woodcock Reading Mastery Test (WRMT) word identification subtest, and a letter name/sound knowledge task. There were no significant differences in age (mean of 5:71), sex, and race. The training group practiced segmentation activities for 20 minutes, four times a week, for 7 weeks. During post-testing, the trained group performed significantly better than the other two groups on the phoneme segmentation task. Furthermore, there was no significant difference between the two control groups. The posttests on the WRMT subtest also showed significant differences among the groups. Thirty-four percent of the treatment group could read four or more words, as compared to $13 \%$ of the language activities group, and $7 \%$ 
of the no intervention group. Ball and Blachman concluded that kindergarten children can be taught phonological awareness skills and the development of these skills assist children with early reading.

Clinical ideas for teaching phonological awareness

Yopp (1992) believes that phonemic awareness can be facilitated through fun games and language play, not only in early school age, but also during the preschool years. Teachers of phonemic awareness, when developing an activity, should first decide on the task and then develop a developmentally appropriate way to engage the child in the task through an activity or game. Tasks that she recommended include sound matching and sound isolation. Also, blending activities can utilize the game "What am I thinking of?" in which the teacher names a category, the children guess, and the teacher gives hints such as "/k/ - /ow/." Sound addition or substitution activities can use the song "someone's in the kitchen with Dinah" and substitute or add sounds during the fefi-fiddly-i-o section. Segmentation activities include teaching to repeat sounds that start or end words in a song and incorporating the separated segmented phonemes in a familiar tune. Yopp stressed that these activities should supplement, and not replace children's interactions with meaningful language and print (Yopp, 1992).

Ball and Blachman (1988) also made suggestions for instructing phonemic awareness. Games can be played that enhance 
blending skills, sound categorization, and segmentation. They created a say-it-and-move-it game in which the children slide chips off of a picture. Each chip represents a sound of the word, and the children manipulate the disks while saying the sound. The children progress from one sound to three sounds. They also recommended adding the grapheme to the disk once the idea of sound-symbol correspondence is learned. They suggested these tasks for the kindergarten curriculum.

\section{Summary}

The literature has shown that phonemic awareness is an important skill for beginning reading. Phonemic awareness is not a natural biologically programmed skill, but through games with words and written language, children can learn to rhyme, isolate sounds from words, and represent words and sounds with symbols. The development of phonemic awareness assists children with learning to read. Many children with phonological and language disorders have difficulties with phonemic segmentation and reading, but it is unknown if children with a history of expressive language delays have these same difficulties. To this researcher's knowledge, there have not been any specific studies designed to compare children with a history of expressive language delays to children with expressive language disorders, and children with normal language development on a phonemic segmentation task. The present study examines this skill. 
CHAPTER III

\section{METHODS AND PROCEDURES}

\section{Subjects}

\section{Subject Recruitment}

The subjects selected for this study were children participating in the Portland Language Development Project (PLDP), a longitudinal study of language acquisition in children with (a) a history of expressive language delay, (b) an expressive language delay and (c) normal language development. At the age of 20-34 months, children whom parents considered slow to begin talking were recruited through newspaper and radio advertisements. Children were also recruited for the PLDP by questionnaire from pediatric clinics in the Portland, Oregon area.

\section{Subject Placement at Intake}

The children were placed into two groups, based on parent report, by using the Language Development Survey (LDS) (Rescorla,1989) (Appendix A). The LDS is a checklist of 300 commonly used words in children's early expressive vocabulary. Rescorla reported that the LDS is a valid and reliable tool for indexing expressive vocabulary size in this age group. The groups 
consisted of (a) toddlers who produced fewer than 50 words at 2034 months, designated as late talkers (LT); and (b) toddlers who produced more than 50 words at 20-34 months, designated as having normal language development (NL). Table I displays the group demographic information at intake. There were no significant differences between groups in areas of socioeconomic levels, sex ratio, and age at intake. They all passed a hearing screening to discount the variable of a hearing loss (Paul, 1991).

\section{Subject Placement At Follow-Up}

In the first grade, The subjects in the present study were again evaluated. Expressive language development was assessed by using the Developmental Sentence Scoring (DSS) analysis (Lee, 1974) (Appendix B). This is a normed speech sample analysis that analyzes children's syntactic sentence structure, and provides percentile rankings for children ages 1:6-8:0. The subjects were then divided into three groups on the basis of DSS scores. One group was comprised of children who were in the LT group at intake, but who received a DSS score of 6.35 or better (the tenth percentile for sixyear-olds) at first grade. This was termed the History of Expressive Language Delay group (HELD) $(n=22)$. A second group was comprised of children who were initially in the LT group at intake and who scored below 6.35 on the DSS at first grade. This was termed the Expressive Language Delay group (ELD) $(\underline{n}=7)$. The third group was comprised of children who were initially assigned to the normal 
Table 1

Group Demographic Information at Intake

\begin{tabular}{|c|c|c|c|}
\hline \multicolumn{3}{|c|}{ Normal Group } & \multirow{2}{*}{$\frac{\text { Late Talking Group }}{29}$} \\
\hline$\underline{\mathrm{n}}$ & & 24 & \\
\hline & Mean & 25.3 & 24.8 \\
\hline \multirow[t]{3}{*}{ Age $^{a}$} & $\underline{\mathrm{SD}}$ & 5.0 & 4.1 \\
\hline & Range & 18.0 & 14.0 \\
\hline & Mean & 2.6 & 2.6 \\
\hline \multirow[t]{3}{*}{ S.E.Sb } & $\underline{S D}$ & 1.4 & 1.0 \\
\hline & Range & 4.0 & 4.0 \\
\hline & Mean & 197.0 & 27.5 \\
\hline \multirow[t]{2}{*}{ \#Words } & $\underline{\mathrm{SD}}$ & 87.9 & 25.4 \\
\hline & Range & 292.0 & 86.0 \\
\hline$\%$ of Males & & $67 \%$ & $72 \%$ \\
\hline
\end{tabular}

aln Months. bBased on Myers \& Bean (1968) adaption of the Hollingshead Four Factor Scale of Social Position. 
language group (NL) $(n=23)$ and who scored above 6.35 on the DSS at first grade. Table 2 displays the group demographic information at follow-up and the mean, standard deviation, and range for the DSS scores.

\section{Procedures}

\section{Procedures for DSS}

The evaluator, a trained graduate student, collected speech samples on audio tape from each subject at the first grade evaluation. The children and their parents played with a farm scene colorform set which included pictures of trees, animals, and other farm objects. The speech samples were later transcribed by the trained graduate student from audio tape into the Systematic Analysis of Language Transcripts (SALT) computer program developed by Miller and Chapman (1981). The utterances were transmitted to the score sheet from the SALT printout and analyzed and scored according to the rules specified by Lee (1974). The first 50 complete noun-verb (subject-object) sentences were analyzed, according to structures the sentences contained in each of eight syntactical categories: indefinite pronouns, personal pronouns, main verbs, embedded secondary verbs, negative markers, conjuctions, interrogative reversals, and wh- question forms. Points were given for each catagory based on the utterance's complexity along a developmental scale. Also, a sentence point was scored for each 
Table 2

Group Demographic Information and DSS Score at Follow-up

\begin{tabular}{|c|c|c|c|c|}
\hline & & NL group & HELD group & ELD group \\
\hline \multicolumn{2}{|l|}{$\underline{n}$} & 24 & 22 & 7 \\
\hline \multicolumn{3}{|c|}{$\%$ of original LT group } & $68.2 \%$ & $31.8 \%$ \\
\hline & Mean & 84.8 & 83.1 & 84.4 \\
\hline \multirow[t]{3}{*}{ Age $^{a}$} & $\underline{\mathrm{SD}}$ & 2.8 & 2.6 & 2.6 \\
\hline & Range & 11.0 & 11.0 & 7.0 \\
\hline & Mean & 2.6 & 2.5 & 3.0 \\
\hline \multirow[t]{3}{*}{ S.E.Sb } & $\underline{\mathrm{SD}}$ & 1.4 & 0.9 & 1.1 \\
\hline & Range & 4.0 & 3.0 & 4.0 \\
\hline & Mean & 8.05 & 7.67 & 5.54 \\
\hline \multirow[t]{2}{*}{ DSS score } & $\underline{\mathrm{SD}}$ & 1.33 & 1.00 & 0.69 \\
\hline & Range & 4.48 & 3.84 & 1.81 \\
\hline \multicolumn{2}{|l|}{$\%$ of Males } & $67 \%$ & $73 \%$ & $71 \%$ \\
\hline
\end{tabular}

aln Months. bBased on Myers \& Bean (1968) adaption of the Hollingshead Four Factor Scale of Social Position. 
utterence that was produced correctly (according to proper English standards). The points were then added which yielded a score for each utterence. Points for the utterances were then summed, which yeilded a total score for the analysis. The total score was divided by 50 to yeild a mean DSS score. This score was then transformed to a percentile based on the norm reference scale provided by Lee (1974). According to Lee (1974) the DSS is a norm referenced instrument which is valid and reliable for evaluating children's syntactical speech sample's, which provides an overall representation of the child's syntactical language development.

Reliability for the Transcription and DSS Scoring

Reliability for the transcription was assessed. To measure the interrater reliability of the speech sample transcription, $10 \%$ of the samples were randomly selected. A second trained graduate student transcribed the middle 100 words from these samples. A point-topoint agreement of $95 \%$ was obtained by dividing the number of words in agreement by the number of words (100).

Reliability for the DSS scoring was also assessed. To check for interrater reliability of DSS scoring, approximately $10 \%$ of the transcriptions were randomly selected. The second trained graduate student, using the rules specified by Lee (1974), scored the utterances for the DSS independently. A point-to-point comparison score of $92 \%$ was found for sentence scoring. This interrater reliability score was found by dividing the total number of 
categorical points in agreement by the total number of categorical points possible.

\section{Procedures for Phonological Awareness task}

The evaluator then administered a phonemic segmentation test to the first grade children. This test was developed by Ball \& Blachman (1988) (Appendix C), who stated that it was adapted from Liberman et al. (1974). The test consists of 34 stiumulus items, of which 32 were used for this study. Two items were not tested due to the complexity of the diphthong /au/, which can be mistaken for two sounds $/ a /$ and $/ u /$. The items divided into three levels: (a) five single-phoneme (vowel only) items, (b) 13 two-phoneme items (2 $\mathrm{CV}, 11 \mathrm{VC}$ ), and (c) 14 three-phoneme items (CVC).

Each child was administered the phonemic segmentation task. The task involved listening to the stimulus and responding by moving disks from a pile for each sound or phoneme in the stimulus. First, the child proceeded through four task demonstrations and training trials in which the examiner provided corrective feedback. The examiner said one phoneme and two phoneme items in the first three demonstrations, and one, two, and three phoneme items in the fourth demonstration. After each demonstration, the child followed the model of the examiner, and moved the disks for each sound in the word. For example, the examiner said the demonstration word "mooo" (as in the word move) and moved a disk from a pile down the table while saying the first sound $/ \mathrm{m} /$ in the item, then a second disk while producing the second sound $/ u /$ in the item. The examiner 
then ran her finger across the disks from left to right as if reading, while saying the sounds in the item. The examiner then asked the child to move the disks down. The child received reinforcement for the correct response during the demonstration items. If the child moved the disks correctly, the examiner said "Now let's do it again to make sure you've got the idea. I'll mix them up and see how you do." If the child made an error on the first demonstration, the examiner said "watch me", and demonstrated the correct response again, then asked the child to do it again. If the error persisted, the examiner modeled the correct response again, but moved to the next demonstration item. After the four demonstration items were administered, the examiner said "Now we'll play the real game. I'll say a word, but I won't show you, because you know how to play the game yourself. You'll show me the sounds in each word with the disks. Ready?" The examiner then began the task. For example, the examiner said the stimulus word "mud". The children were scored on a binary basis, either a plus or minus was recorded for each item. If the child correctly moved the correct number of disks on the table for the stimulus items, then the item was marked correct. If the child did not move the correct number of disks, the stimulus item was considered incorrect. The 32 stimulus items were administered to the children. The level of one, two, and three phoneme items were randomly distributed throughout the test. After the test was completed, the examiner summed the number correct for each phoneme level and added all the items to produce a score for the total number correct. 
Analysis

The dependent variable was the number of words correctly segmented into sounds. Descriptive and inferential statistics were used. The descriptive statistics included a measure of central tendency and a measure of variability. Because the data compiled were along a ratio scale, inferential statistics were performed. To determine if there was a significant difference among the three groups at each syllable level and on the total number of correct responses, a one way analysis of variance (ANOVA) test was calculated at the .05 confidence level. An ANOVA was computed for the four variables; (a) one phoneme, (b) two phonemes, (c) three phonemes, and (d) total score. 
CHAPTER IV

RESULTS AND DISCUSSION

Results

The questions asked in this study were intended to determine if there was a significant difference in the phonemic segmentation skills among the three diagnostic groups of six-year-old children. The four specific questions asked were: (a) Is there a significant difference among the three groups of children in the number of correct responses on a phonological segmentation test at the onephoneme level? (b) Is there a significant difference among the three groups of children in the number of correct responses on a phonological segmentation test at the two-phoneme level? (c) Is there a significant difference among the three groups of children in the number of correct responses on a phonological segmentation test at the three-phoneme level? (d) Is there a significant difference among the three groups of children in the total number of correct responses on a phonological segmentation test?

ANOVA was used to determine if there was a significant difference among the three groups for each of the dependent variables, the number of words correctly segmented into sounds. The means, standard deviations, and ranges for each group are 
provided in Table 3. The possible number correct was five for the one phoneme level, 13 for the two phoneme level, 14 for three phoneme level and 32 for the total number correct. The raw data for each subject on the phonological segmentation test is provided in Appendix E.

To determine if there was a significant difference $(\underline{p}<.05)$ among the three groups on the four dependent variables, an ANOVA test was completed. The results of the ANOVA are provided in Table 4. A significant difference was determined to exist only at the two phoneme level ( $\mathrm{p}=.025)$.

To determine which pairs of means were significantly different at the two phoneme level, post hoc testing was completed using a Tukey multiple comparison. This analysis compared the scores among the three groups of subjects. These results are listed in Table 5. As shown in the table, the difference was found to be between the Normal group and the ELD group, as well as between the HELD and ELD group.

Other significant differences were not found, although the difference at the one phoneme level approached significance $(\mathrm{p}=.052)$. Performance within each group at the three phoneme varied greatly and results suggested that the HELD and the ELD group did poorer than the Normal group. Results for the total score revealed no significant difference. 
Table 3

Mean, Standard Deviation, and Range of Each Dependent Measure For Each of the Three Diagnostic Groups

\begin{tabular}{lllll}
\hline $\begin{array}{l}\text { MEASURE } \\
\text { (\# of items) }\end{array}$ & GROUP & MEAN & SD & RANGE \\
\hline
\end{tabular}

One Phoneme

(5)

$\begin{array}{llll}\text { Normal } & 4.92 & 0.28 & 1 \\ \text { HELD } & 4.95 & 0.21 & 1 \\ \text { ELD } & 4.57 & 0.79 & 2\end{array}$

Two Phonemes

$\begin{array}{llll}\text { Normal } & 11.62 & 1.21 & 5 \\ \text { HELD } & 11.82 & 1.14 & 4 \\ \text { ELD } & 10.00 & 3.00 & 7\end{array}$

Three Phonemes

(14)

$\begin{array}{lrrr}\text { Normal } & 10.46 & 4.50 & 14 \\ \text { HELD } & 7.36 & 5.12 & 15 \\ \text { ELD } & 9.00 & 6.32 & 14\end{array}$

Total Score

$\begin{array}{llll}\text { Normal } & 27.00 & 5.12 & 17 \\ \text { HELD } & 24.09 & 5.54 & 17 \\ \text { ELD } & 23.57 & 8.50 & 21\end{array}$


Table 4

Results of the One-Way Analysis of Variance (ANOVA)

\begin{tabular}{lcc}
\hline MEASURE & F Ratio & $\underline{P}<$ \\
One Phoneme & 3.147 & 0.052 \\
Two Phonemes & 3.992 & 0.025 * \\
Three Phonemes & 2.186 & 0.123 \\
Total Score & .819 & 0.173 \\
\hline *significant & &
\end{tabular}

Table 5

Results of the Tukey Multiple Comparisons Test Between Groups at the Two Phoneme Level

\begin{tabular}{llll}
\hline & Normal & HELD & ELD \\
Normal & 1.000 & & \\
HELD & 0.903 & 1.000 & \\
ELD & $0.042 *$ & $0.021 *$ & 1.000 \\
\hline${ }^{*} \mathrm{p}<.05$ & & & \\
\hline
\end{tabular}




\section{Discussion}

The results of this study indicate that children who are slow to develop expressive language, but catch up to their peers in expressive language, do not perform significantly different from their normally developing peers in the skill of phonemic segmentation. Children who remain expressively language delayed are significantly behind their peers in segmenting two sounds, show a nonsignificant trend in the same direction at the one phoneme level, and perform more poorly at the three phoneme level, but the difference does not reach significance. The consistent trend was that the normal group performed better than the ELD group at all levels.

The difference in performance at the one phoneme level approaches significance $(\mathrm{p}=.052)$. The small standard deviation indicates that the children did not vary widely on this task. It is known that there is a progression in phonological awareness (Liberman et al, 1974; Fox \& Routh, 1975). The high mean scores of the normal and HELD group indicate that most of these children know that one phoneme represents one sound.

At the two phoneme level, there was a significant difference in performance among the groups. The difference was found to be between ELD children, and the other two groups. The absolute difference in the means for all the groups was small, but the standard deviation for the ELD group was larger than the other groups. This indicates that there was a wider variance in the 
number of correct items at this level than for the other two groups of children. The significant difference may be due to the variability of the scores obtained by the ELD children. It is unknown why the variability was wide for the ELD children. It is possible that some of the children in this group have had Speech-Language treatment with an emphasis on the phonological structure of words. It may also be because some of the children have been trained in phonological awareness.

Another possibility for the difference is the amount of literacy socialization that occurs in the home. VanKleeck and Schuele (1987) pointed out that many children who have an awareness of language are socialized to literacy through stories, and are bombarded every day with literacy artifacts such as alphabet blocks, t-shirts with writing on them, and other print related materials. In first grade, when the children were evaluated for this study, the ELD children's S.E.S. lowered, but the HELD children's S.E.S. stayed relatively the same. It is possible that literacy socialization occurs more often in high to middle class populations. This could be a reason for the difference among the groups.

At the three phoneme level, all the groups had an extremely large range (14-15). The ELD group had the largest standard deviation (6.3), which indicates that the children in this group varied as to their performance level with three phonemes. If there were more children in the ELD group a difference may have been found,since the standard deviation was so large. Also of importance 
is the wide standard deviation of the HELD children at this level (5.1), indicating that some children scored very low on this task.

The normal group scored an average of 10.5 out of 14 possible correct, which is only $75 \%$ correct. This low score indicates that the normally developing children had difficulty with the three phoneme level segmentation task, which has been shown to correlate with later reading development. None of the groups did well on this task and the difference in group variability was large. This may be the basis for the failure to find a significant difference. VanKleeck and Schuele (1987) point out that children who enter school without literacy socialization and a decreased knowledge of phonological awareness have more difficulties with reading. Especially when instruction in reading is based upon the assumption that children know about the phonological structure of sounds. The whole word, or whole language approach in its pure form does not teach to phonological awareness. It is possible that the children in the normal group have been instructed in whole language without learning about phonological awareness. The children for this study were selected from Portland. Portland public schools currently use a whole-language model. Perhaps some of the children who have mastered oral language are having difficulty with phonemic segmentation due to a lack of training. It is known that there are differences between oral and written language (Ball \& Blachman, 1988; Blachman, 1989; Kamhi \& Catts, 1989; Vellutino, 1991). Some children who develop oral language may have more difficulty with written language and need specific training in phonological 
awareness, which leads to early reading success (Ball \& Blachman, 1988).

When totaling all the scores, the ELD group scored lower than the normal group. This continued the trend that occurred at all levels of the task. The standard deviation was large for all the groups, but the ELD group had the largest (8.5) for the total number correct, indicating that the group that scored the poorest also had the largest variability throughout all the levels of the task. 


\section{CHAPTER V}

\section{SUMMARY AND IMPLICATIONS}

\section{Summary}

Several researchers have shown that the skill of phonemic segmentation is related to the skill of reading. Poor readers have poor segmentation skills and vice versa (Blachman, 1984; Blachman, 1989; Bradley and Bryant, 1985; Catts, 1989; Juel et al., 1986; Kamhi \& Catts, 1989; Liberman et al, 1974; Mann \& Liberman, 1984; Stanovich et al, 1984; Vellutino, 1991; Wagner, 1986; Wagner \& Torgesen, 1987; Wallach et al., 1977). These researchers showed that acquiring the skill of phonemic segmentation is a learned process that progressively develops in the child. The skill of knowing that words can be segmented into sounds is not part of the natural biological process of language development, and is one of many skills needed for metalinguistic awareness which is necessary for success in school.

The purpose of this study was to compare the phonemic segmentation skills in three diagnostic groups of first grade children: (a) Children with a history of expressive language delay who caught up to their peers, (b) children who had a history of expressive language delay and did not catch up to their peers in oral 
expressive language by first grade, and (c) children who developed normal expressive language.

These children were compared along four dependent variables. The following questions were examined:

1. Is there a significant difference among the three groups of children in the number of correct responses on a phonological segmentation test at the one-phoneme level?

2. Is there a significant difference among the three groups of children in the number of correct responses on a phonological segmentation test at the two-phoneme level?

3. Is there a significant difference among the three groups of children in the number of correct responses on a phonological segmentation test at the three-phoneme level?

4. Is there a significant difference among the three groups of children in the total number of correct responses on a phonological segmentation test?

The children participated in a phonemic segmentation task. The data of the number correct were analyzed using descriptive and inferential statistics. The means, standard deviation, and range were calculated for each of the questions, and a one-way Analysis of variance (ANOVA) was used to determine if there was a difference among the three groups.

Utilizing an ANOVA test, a significant difference was found among the groups at the two phoneme level. A Tukey test revealed the difference was between the ELD group and the normal group, as well as the HELD group and the Normal group. The one phoneme level 
approached significance and the three phoneme level was not significant, but the HELD children scored poorer than the other two groups. The pattern that pertained throughout all levels was that the ELD children scored poorer than the normal group. The total number correct, which consisted of all levels added together, also resembled this pattern.

\section{Implications}

\section{Research}

Future research in the area phonological awareness is needed. Although first grade is a good age to test children in this skill, follow-up procedures would provide more information about the late-talkers as a group. Future reading tasks could be correlated with the phonemic segmentation task to better understand the importance of the skill of phonological awareness in first grade, and to find out if the children who are expressively language delayed still exhibit difficulties, while the normally developing children may progress at a faster rate.

Phonemic segmentation training could be administered to late talking and normally developing kindergarten children. Pre and posttesting could be administered to the children. A research project such as this could help to reveal if training children with a history of slow expressive language development in the ability to segment words into sounds makes a difference. Since speech-language pathologists are beginning to have a role in developing phonemic 
awareness skills with language delayed and disordered children (Chabon \& Prelock, 1987), this research would be an important consideration.

Another consideration for further research is to test this population in other areas of phonological awareness, such as phoneme deletion, invented spelling, and dynamic phoneme segmentation, which is discussed by Spector (1992). Other areas of metalinguistic awareness which may be related to reading achievement should also be assessed, including, lexical retrieval, rapid naming, phonological encoding in noise, expressive ability of complex phonological sequences (at a later age), and verbal memory.

Another possible longitudinal study would be to distribute children who exhibit language delays as toddlers into two diagnostic groups at the age of three. One group could consist of children who produce expressive phonological process errors in their speech based on a phonological process analyisis, and the other group could consist of children whose language expression is not phonologicaly impaired, but expressively impaired in another area of language, such as syntax or semantic skills based on a given measure. In first grade these children could be administered the same phonemic segmentation task used in this study. Then a follow-up of reading development could be assessed at a later date. Research such as this could assist speech-language pathologists in determining the areas of early expressive language delay that predict phonological awareness and reading deficits. A cross-sectional study similar to this was designed by Webster \& Plante (1992). 


\section{Clinical}

This study found that all the groups had difficulty segmenting words into sounds at the three phoneme level. The children in the ELD group scored significantly more poorly at the two phoneme level. Since it is known that the skill of phonemic segmentation is indeed crucial for beginning reading, the findings of this study suggest that the skill of phonemic segmentation should be taught to children with language disorders.

This study also showed that the normal children scored lower than this author expected. Therefore, the speech-language pathologist should inform preschool teachers that games with words that facilitate phonological awareness would also maximize the children's future reading potential. The literature contains clinical ideas for teaching phonemic awareness to young children (Ball \& Blachman, 1988; Yopp, 1992) and information on how to follow the child's development of phonological awareness (Jenkins \& Bowen, 1994). Screening assessment procedures in preschools may be implemented by speech-language pathologists to detect the children who are exhibiting early warning sings of reading difficulty in the later school years (Swank, 1994).

Furthermore, although there were no significant differences between normally developing children and the HELD children, this study's results, when looking at means and standard deviations, imply that when children are slow to develop expressive language, some of them may still lag behind normally developing children in phonemic segmentation skills. There is a fundamental link between 
phonological awareness and reading. Teaching phonological awareness to children who have a history of expressive language delays and to children who have phonological and language disorders would be a preventive measure to guard against early reading deficits. Phonological awareness should be targeted before kindergarten to facilitate the early onset of the phonological awareness development pattern (Jenkins \& Bowen, 1994). Rather than waiting to see if the child catches up in expressive language, which does occur, speech-language pathologists, teachers, and parents can facilitate certain metalinguistic skills, such as phonological awareness, at an early age to provide children with the means to succeed in school. 


\section{REFERENCES}

Ball, E. W., \& Blachman, B. A. (1988). Phoneme segmentation training: Effect on reading readiness. Annals of Dyslexia, 38, 208-225.

Blachman, B. A. (1984). Language analysis skills and early reading acquisition. In G. P. Wallach, \& K. G. Butler, (Eds.), Language learning disabilities in school-age children (pp. 271-287). Baltimore, MD: Williams \& Wilkins.

Blachman, B. A. (1989). Phonological processing deficits and reading. In A. G. Kamhi, \& H. W. Catts (Eds.), Reading disabilities: A developmental language perspective, (pp. 133158). Boston: College-Hill.

Bradley, L., \& Bryant, P. E. (1983). Categorizing sounds and learning to read-a causal connection. Nature, $\underline{310}$, 419-421.

Bradley, L., \& Bryant, P. (1985). Rhyme and reason in reading and spelling. Ann Arbor: University of Michigan Press.

Bruck, M., \& Treiman, R. (1990). Phonological awareness and spelling in normal children and dyslexics: The case of initial consonant clusters. Journal of Experimental Child Psychology, 50, 156-178.

Catts, H. W. (1986). Speech production/phonological deficits in reading-disordered children. Journal of Learning Disabilities, 19 , 504-508.

Catts, H. W. (1989). Phonological processing deficits and reading disabilities. In A. G. Kamhi, \& H. W. Catts (Eds.), Reading disabilities: A developmental language perspective (pp. 101132). Boston: College-Hill. 
Chabon, S. S., \& Prelock, P. A. (1987). Approaches used to assess phonemic awareness: There is more to an elephant than meets the eye. Journal of Childhood Communication Disorders, 10, 125156.

Eimas, P. D. (1985). The perception of speech in early infancy. Scientific American, 252, 46-52.

Fox, B., \& Routh, D. K. (1975). Analyzing spoken language into words, syllables, and phonomes: A developmental study. Journal of Psycholinguistic Research, 4, 331-442.

Fox, B., \& Routh, D. K. (1980). Phonemic analysis and severe reading disability in children. Journal of Psycholinguistic Research, $\underline{9}$, 115-119.

Gilmore, J. V., \& Gilmore, E. C. (1968). Gilmore Oral Reading Test. New York: Harcourt, Brace \& World.

Gombert, J. E. (1992). Metalinguistic development. Chicago: University of Chicago press.

Jenkins, R., \& Bowen, L. (1994). Facilitating development of preliterate children's phonological abilities. Topics in Language Disorders, 14, (2), 26-39.

Juel, C., Griffith, P. L., \& Gough, P. B. (1986). Acquisition of literacy: A longitudinal study of children in first and second grade. Journal of Educational Psychology, 78, 243-254.

Kamhi, A. G., \& Catts, H. W. (1989). Language and reading:

Convergences, divergences, and development. In A. G. Kamhi, \& H. W. Catts (Eds.), Reading disabilities: A developmental language perspective (pp. 1-34). Boston: College Hill.

Lee, L (1974). Developmental sentence analysis. Evanston, IL: Northwestern University Press.

Liberman, I. Y., Shankweiler, D., Fischer, F. W., \& Carter, B. (1974). Explicit syllable and phoneme segmentation in the young child. Journal of Experimental Child Psychology, 18, 201-212. 
Mann, V. A. (1987). Phonological awareness: The role of reading experience. In Bertelson, P. (Ed.), The Onset of Literacy: Cognitive Processes in Reading Acquisition (pp. 31-44). Cambridge, MA: MIT Press.

Mann, V. A., \& Liberman, I. Y. (1984). Phonological Awareness and verbal short-term memory. Journal of Learning Disabilities, 17 , 592-599.

Miller, J. F., \& Chapman, R. S. (1981). Systematic Analysis of Language Transcripts, Madison: University of Wisconsin Language Analysis Lab.

Meyers, J. K., \& Bean, L. L., (1968). A decade later: A follow-up of social class and mental illness. New York: Wiley \& Sons.

Paul, R. (1991). Profiles of toddlers with slow expressive language development. Topics in Language Disorders, 11 (4), 1-13.

Paul, R. (1993). Patterns of development in late talkers: Preschool years. Journal of Childhood Communication Disorders, 15, (1), 714.

Perfetti, C. A., Beck, I., Bell, L. C., \& Hughes, C. (1987). Phonemic knowledge and learning to read are reciprocal: A longitudinal study of first grade children. Merrill-Palmer Quarterly, 33, 283317.

Read, C., Yun-Fei, Z., Hong-Yin, N., \& Bao-Qing, D. (1987) The ability to manipulate speech sounds depends on knowing alphabetic writing. In Bertelson, P. (Ed.), The Onset of Literacy: Cognitive Processes in Reading Acquisition. (pp. 31-44). Cambridge, MA: MIT Press.

Rescorla, L. (1989). The Language Development Survey: A screening tool for delayed language in toddlers. Journal of Speech and Hearing Disorders, 54, 587-599.

Spector, J. E. (1992). Predicting progress in beginning reading: Dynamic assessment of phonemic awareness. Journal of Educational Psychology, 84, 353-363. 
Stanovich, K. E., Cunningham, A. E., \& Cramer, B. B. (1984). Assessing phonological awareness in kindergarten children: Issues of task comparability. Journal of Experimental Child Psychology, 38 , 175-190.

Swank, L. K. (1994). Phonological coding abilities: Identification of impairments related to hpnologically based reading problems. Topics in Language Disorders, 14, (2), 56-71.

Torgesen, J. K., Morgan, S. T., \& Davis, C. (1992). Effects of two types of phonological awareness training on word learning in kindergarten children. Journal of Educational Psychology, 84, 364-370.

Trieman, R. (1991). Phonological awareness and its roles in learning to read and spell. In Sawyer, D. J. \& Fox B. J. (Eds.), Phonological Awareness in Reading: The Evolution of Current Perspectives ( $\mathrm{pp}$. 159-190). New York: Springer-Verlag.

VanKleeck, A., \& Schuele, M. C., (1987). Precursors to literacy: Normal development. Topics in Language Disorders, Z(2), 13-31.

Vellutino, F. R. (1991). Introduction to three studies on reading acquisition: Convergent findings on theoretical foundations of code-oriented versus whole-language approaches to reading instraction. Journal of Educational Psychology, 83, 437-443.

Vellutino, F. R., \& Scanlon D. M. (1987). Phonological coding, phonological awareness, and reading ability: Evidence from a longitudinal and experimental study. Merrill-Palmer Quarterly, 33. 321-363.

Wagner, R. K. (1986). Phonological processing abilities and reading: Implications for disabled readers. Journal of Learning Disabilities, 19, 623-630.

Wagner, R. K., \& Torgesen, J. K. (1987). The nature of phonological processing and its causal role in the acquisition of reading skills. Psychological Bulletin, 101, 192-212. 
Wallach, L., Wallach, M. A., Dozier, M. G., \& Kaplan, N. W. (1977). Poor children learning to read do not have trouble with auditory discrimination but do have trouble with phoneme recognition. Journal of Educational Psychology, 69, 36-39.

Webster, P. E., \& Plante, A. S. (1992). Effects of phonological impairment on word, syllable, and phoneme segmentation and reading. Language, Speech, and Hearing Services in Schools, 23, 176-182.

Yopp, H. K. (1992). Developing phonemic awareness in young children. The Reading Teacher, 45, 696-703. 
APPENDIX A

\section{LANGUAGE DEVELOPMENT SURVEY}

Rescorla, L. (1989). The Language Development Survey: A screening tool for delayed language in toddlers. Journal of Speech and Hearing Disorders, $\underline{54}, 587-599$. 


\section{Language Development Survey}

Please check off each word that your child says SPONTANEOUSLY (not just imitates or understands). It's okay to count words that aren't pronounced clearly or are in "baby talk" ("baba" for bottle.).

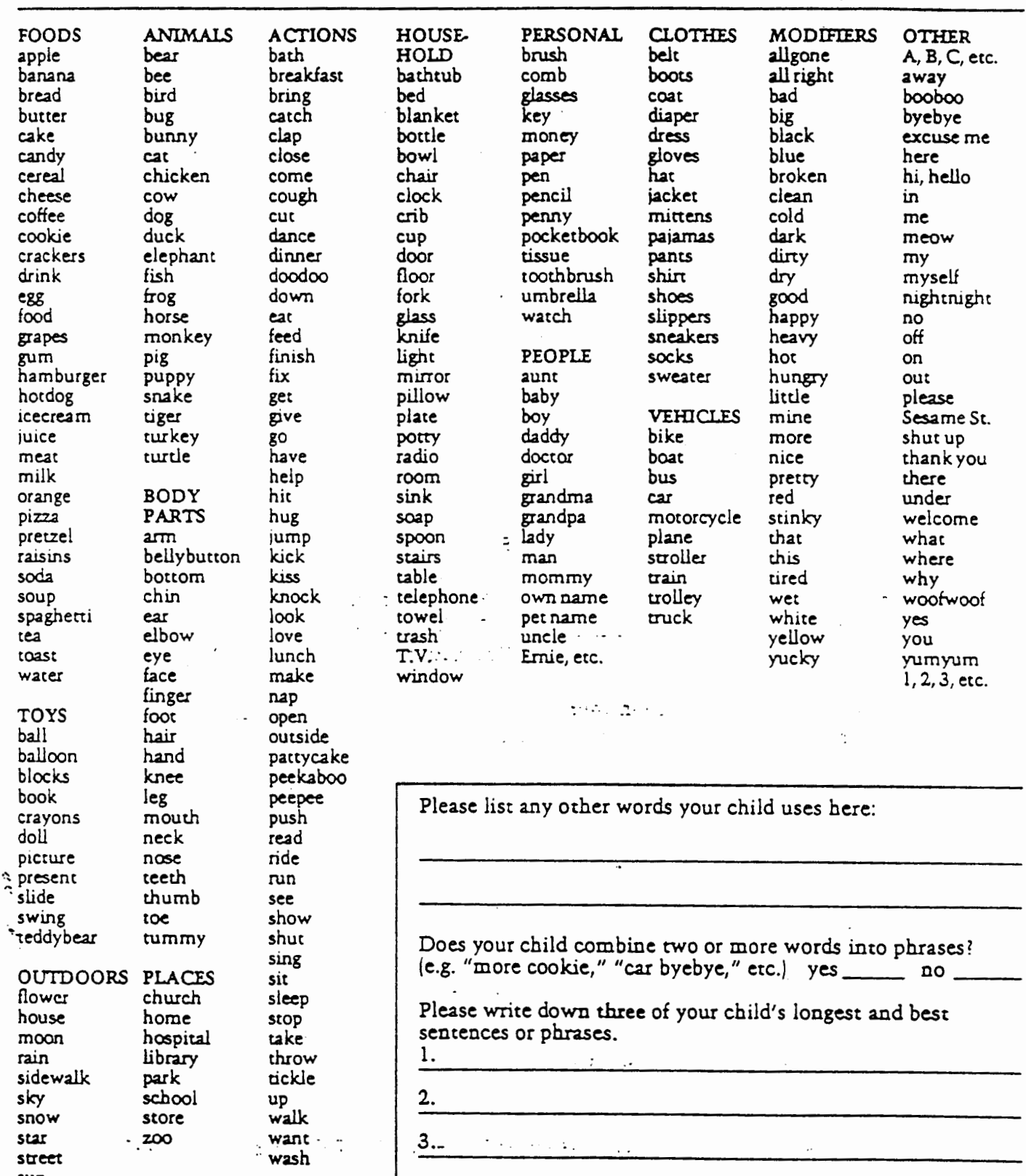




\author{
APPENDIX B \\ DEVELOPMENTAL SENTENCE SCORING (DSS) REWEIGHTED SCORE SHEET \\ AND PERCENTILE GRAPH \\ Lee, L (1974). Developmental sentence analysis. Evanston, IL: \\ Northwestern University Press.
}


Chart 8. The Developmental Sentence Scoring (DSS) Reweighted Scores

\begin{tabular}{|c|c|c|c|c|c|c|c|c|}
\hline SCOR: & $\begin{array}{l}\text { INDEFINITE PRONOUNS } \\
\text { OR NOUN MODIFIERS }\end{array}$ & $\begin{array}{l}\text { PFRSONAL } \\
\text { PHONOUNS } \\
\end{array}$ & MAIN VE:RBS & SECONDARY VERBS & NECATIVES & CONJUNCTIONS & $\begin{array}{c}\text { INTERROGATIVE } \\
\text { REVERSAIS } \\
\end{array}$ & WH-QUESTIONS \\
\hline 1 & it, shis,.that & 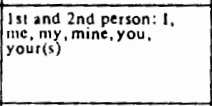 & 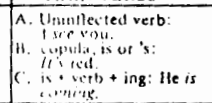 & & 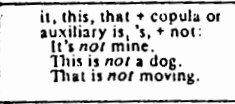 & & $\begin{array}{l}\text { Reversal of copula: } \\
\text { isn' it red" were they } \\
\text { there? }\end{array}$ & \\
\hline 2 & & $\begin{array}{l}\text { 3rd persun he, him, his. } \\
\text { she, her, hers }\end{array}$ & 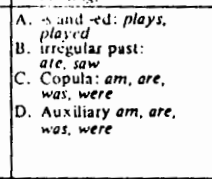 & 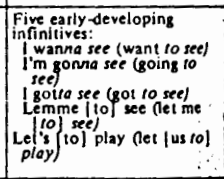 & & & & 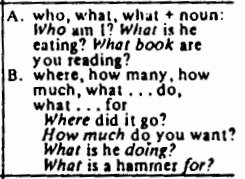 \\
\hline 3 & 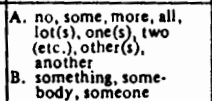 & 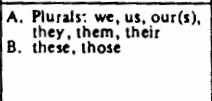 & & 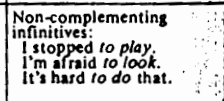 & & and & & \\
\hline 4 & $\begin{array}{l}\text { hothing, nobody, none, } \\
\text { no one }\end{array}$ & & 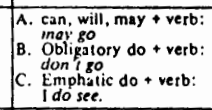 & 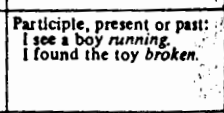 & $\cos ^{2} t, 00 n^{\prime} t$ & - & 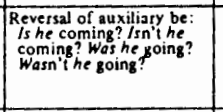 & \\
\hline 5 & & 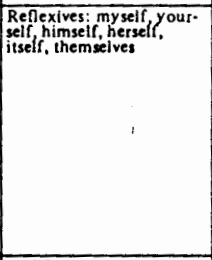 & & 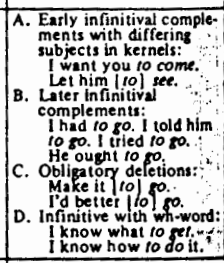 & isn't, won't & $\begin{array}{l}\text { A. but } \\
\text { B. bo, nnd so, so that } \\
\text { C.: of: if }\end{array}$ & & 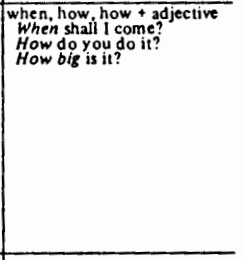 \\
\hline 6 & & 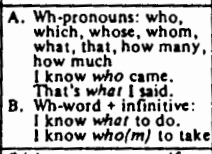 & 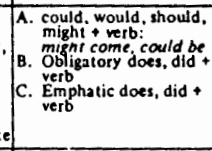 & & & because & 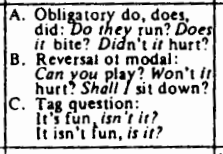 & \\
\hline 7 & 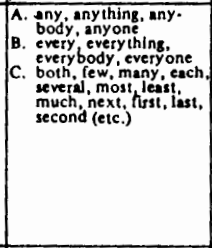 & 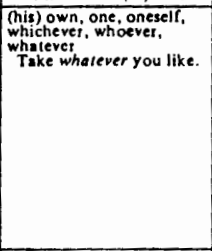 & 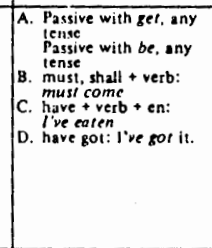 & 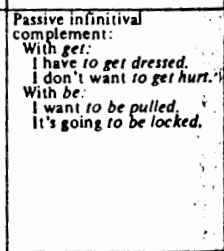 & 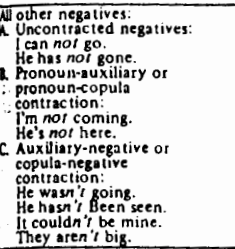 & & & 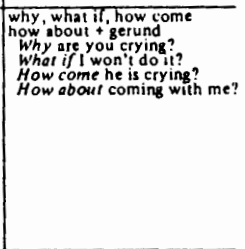 \\
\hline 8 & s & & 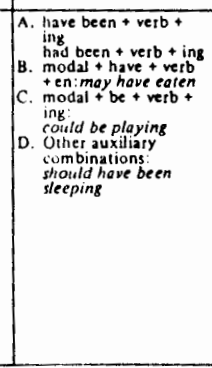 & $\begin{array}{l}\text { Gerund: } \\
\text { Swinging is fun. } \\
\text { Ilike fishlng } \\
\text { He viarned faughing. }\end{array}$ & & 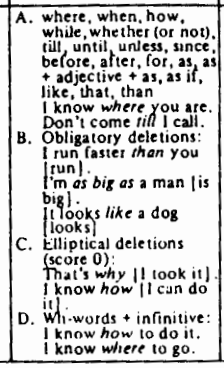 & 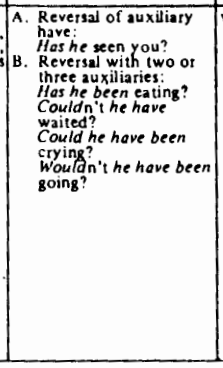 & 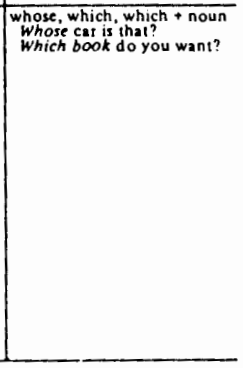 \\
\hline
\end{tabular}




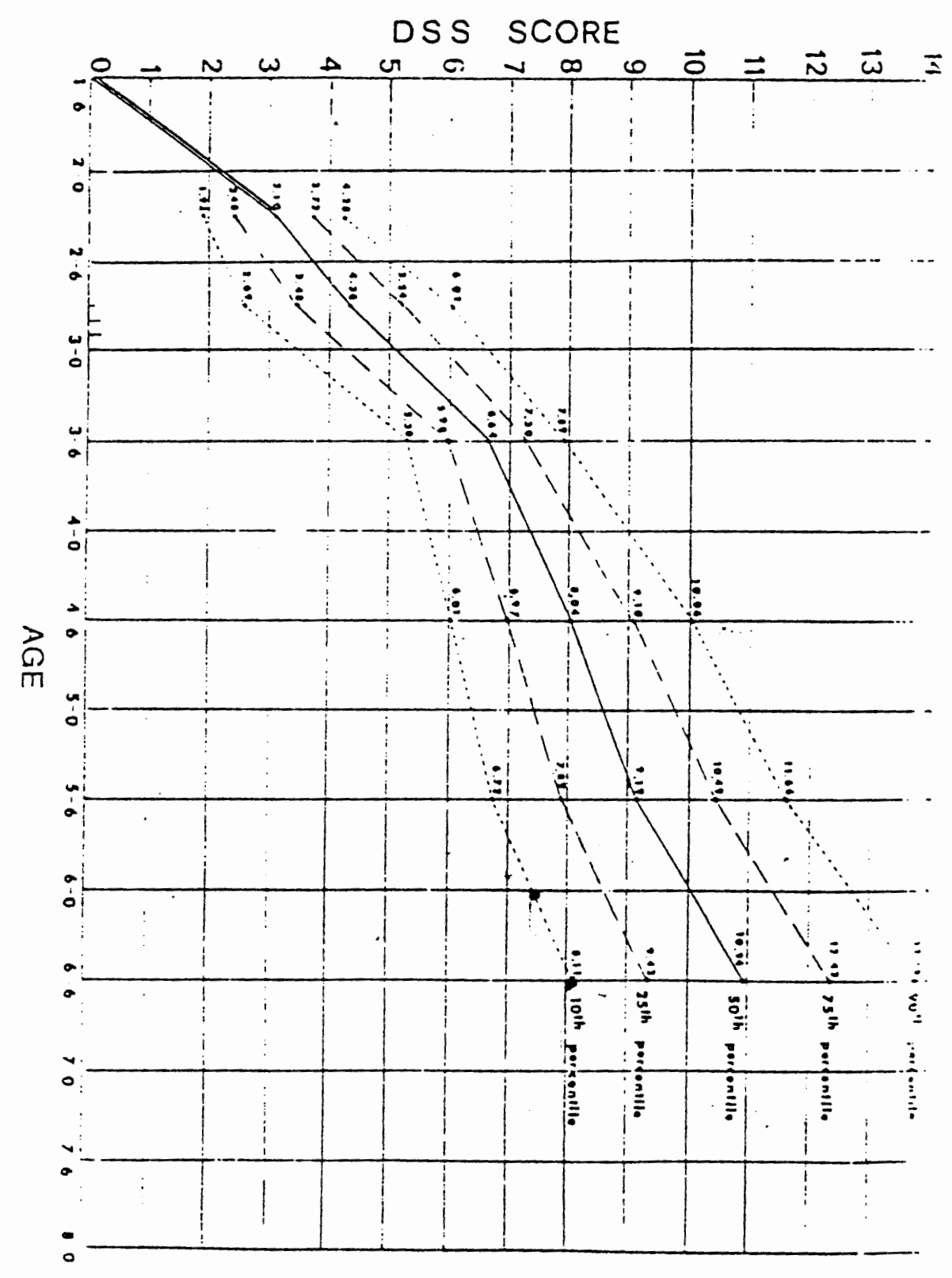


APPENDIX C

PHONEME SEGMENTATION TEST

Ball, E. W. \& Blachman, B. A. (1988). Phoneme segmentation training: Effect on reading readiness. Annals of Dyslexia, 38, 208-225. 


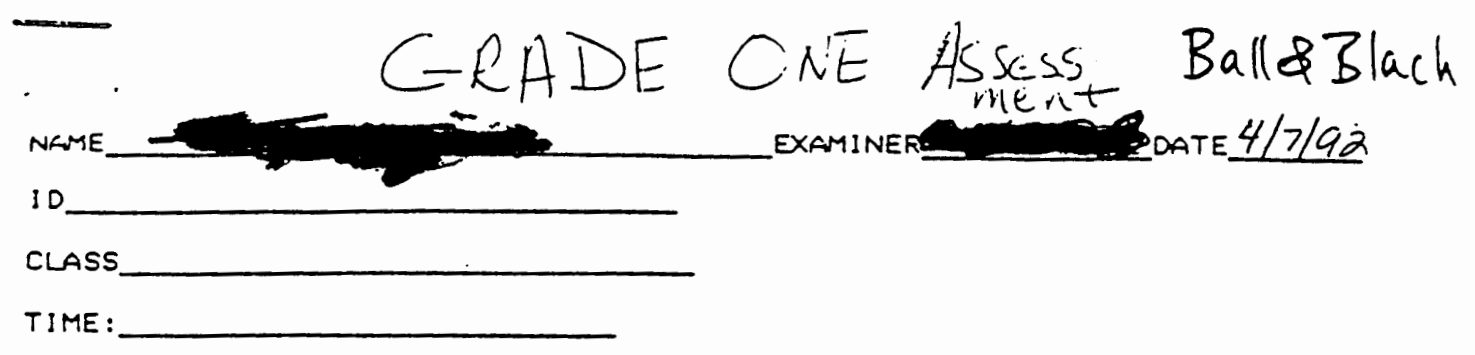

PHONEMIC SEGMENTATIDN TASKS

DIRECTIONS:

FIRST WE ARE GOING TO DO SOME WORK WITH THE LITTLE SOLNOS IN WOROS.

I'LL SHOW YOU HOW.

ARE YOU READY?

DEMONSTRATE FIRST:

IN DEMONSTRATION, SAY THE WORO ONCE.

THEN SAY IT MORE SLOWLY WITH A PAUSE BETWEEN EACH PHONEME AS CHIPS ARE PULLED OUT.

REPEAT THE WORD AS YOU RUN YOUR FINGER ACROSS THE CHIPS FROM LEFT TO RIGHT.

STEP QNE: EXAMINER DEMONSTRATES THE FIRST TRAINING TRIAL.

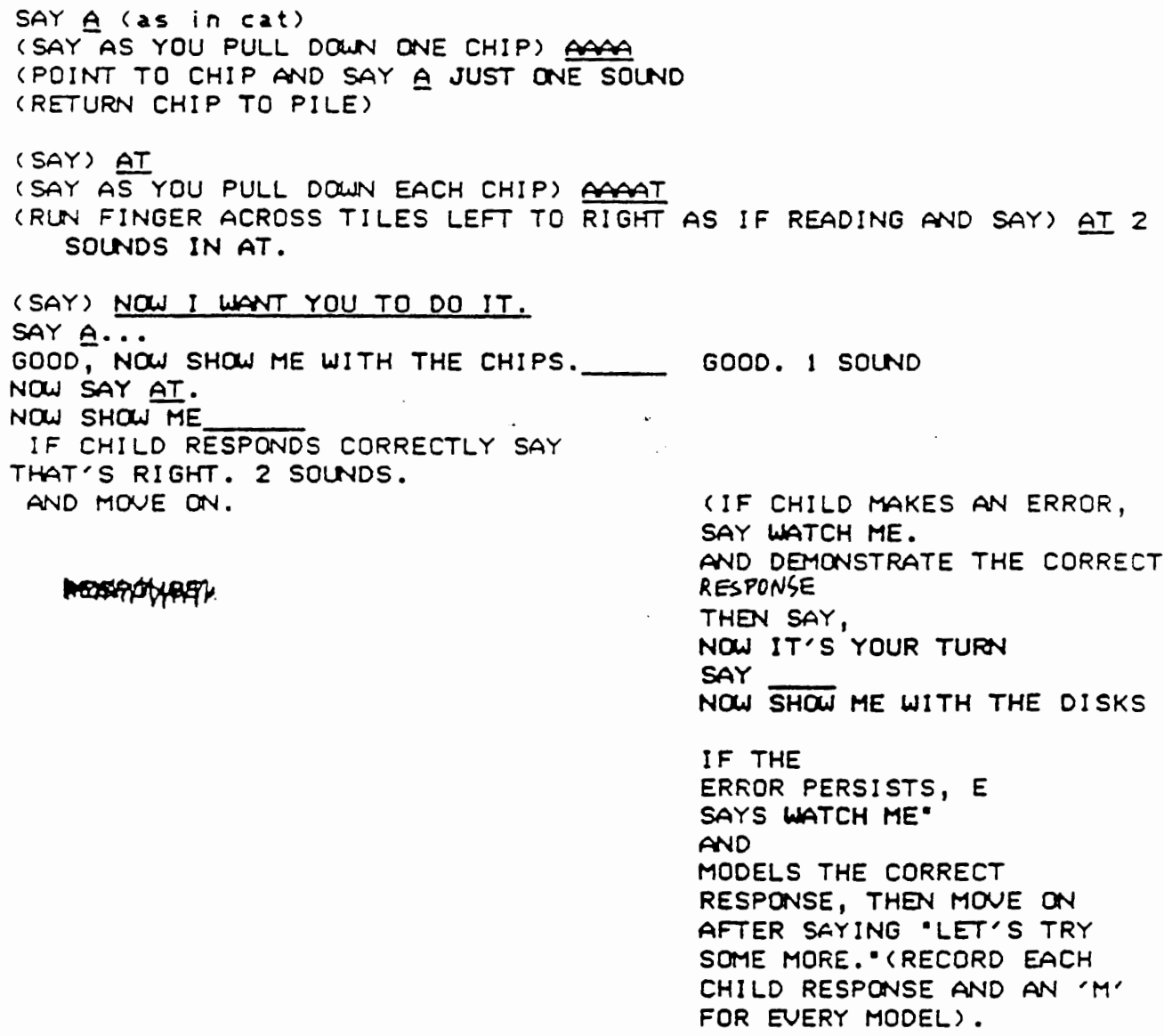




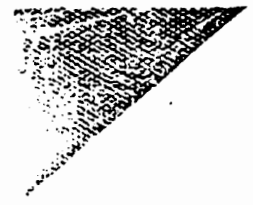

SUMMAPY: IF A CHILD MAKES AN ERPOR, THEY ARE SHOWN HOW TO DO IT AGAIN AND GIUEN THE OPFORTUNITY TO TRY IT AGAIN. IF THEY ERR AGAIN, THE E DEMONSTRATES THE CORRECT RESPONSE ONCE MORE, BUT THEN CONTINUES ON TO THE NEXT ITEM.

IF THE CHILD ATTEMPTS TO RESPOND BEFORE YOU ARE FINISHED DEMONSTRATING, RAISE YOUR HAND (AS IN HALT) ANO CONTINUE DEMONSTRATING... RATHER THAN USING WORDS.

THE RECORDING MAY LDOK LIKE: 4M3M (CHILD INCORRECTLY MOUED \& OISKS, E MOUELED, CHILD INCORRECTLY MOVED 3 DISKS, E MODELED).

STEP 2: (SAY) NOW, LETS DO IT AGAIN TO MAKE SURE YOU UE GOT THE IDEA. I'LL MIX THEM UP AND HCW YOU DO.

SAY AT .....

NOW SHOW ME WITH THE CHIPS

SAY A GOOD. 2 SOUNDS IN AT.

NOW SHOW ME WITH THE CHIPS RIGHT. I SOUND. 
STEP 3: "NOW LETS TRY SOME MORE. I'LL DO IT FIRST."

\section{CDEMONSTRATION IS}

CONTINUED WITH THE NEXT

THREE TPAINING TRIALS,

FOLLOWING ALL PROCEDURES IN

2) DEMONSTRATE FIRST

STEPS 1 AND 2.

00

MOO

(MIX UP) 00

3) DEMONSTRATE FIRST

(MIX UP)

UP

U

4) DEMONSTRATE FIRST

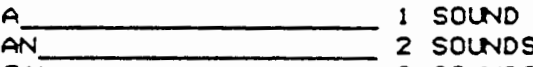

(MIX UP)

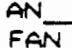

3 SOUNDS

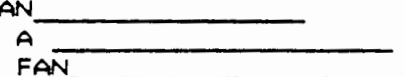

NOW WE'LL PLAY THE REAL GAME. I'LL SAY A WORD, BUT I WON'T SHOW YOU, BECAUSE YOU WNOW HOW TO PLAY THE GAME YOURSELF. YOU'LL SHOW ME THE SOUNDS IN EACH WORO WITH THE DISKS: READY?

$\underbrace{\infty}_{2 . \text { rut }} \circ(\operatorname{not}) \frac{t}{t}$

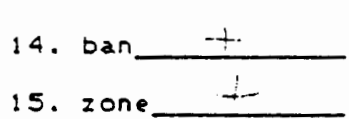

$\checkmark C$

3. i

VY. Us.

(1).

$\mathrm{Cl}^{\mathrm{V}} \mathrm{e}$.

C. $2 \mathrm{~m}-$.

$\checkmark C 4$.

ת

5. cake

18. rip

(16) e (set)

19. mat

$V C 7$. ache

$\mathbf{2 0 . i ( i t )}$

8. $\operatorname{mud}$

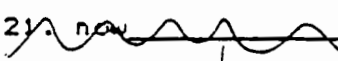

VC $\dot{9}$. $\therefore$...

22 .

30. bum

31. sun

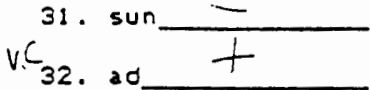

33. $+i$

$\mathrm{CV}_{34}$. $10 \mathrm{w}+1$

VC $10.00 \frac{-}{11.1000 \quad \frac{-}{-}}$ ${ }_{12} \mathrm{C}_{23}$

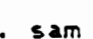
$+$

23. is

24

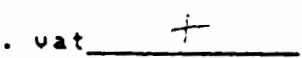

YC 12 . it

--

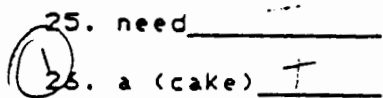

TOTAL CORPECT 32

1 PHONEME 5

2 PHONEMES

3 PHONEMES

$\mathrm{VC:3}$. a

$\div$

26. a (cake) - 
APPENDIX D

HUMAN SUBJECTS RESEARCH WAIVER 


\section{OFFICE OF GRANTS AND CONTRACTS}

DATE: $\quad$ April 30, 1993

TO: David TAndrews'

FROM: Martha Balshem, Chair, HSRRC, 1992-93 Man tha Bolshem fith

RE: $\quad$ HSRRC Waived Review of Your Application titled "A Comparative Study of Phonetic Segmentation Skills in First Grade Children..."

Your proposal is exempt from further HSRRC review, and you may proceed with the study.

Even with the exemption above, it was necessary by University policy for you to notify this Committee of the proposed research and we appreciate your timely attention to this matter. If you make changes in your research protocol, the Committee must be notified.

c. Office of Graduate Studies

waiver.mem 


\section{APPENDIX E}

RAW DATA FOR THE THREE GROUPS ON THE DSS AND THE PHONOLOGICAL AWARENESS TEST 
HELD Group Statistics

\# CA/I CA/F SEX SES DSS PA1 PA2 PA3 PAT LDS $\begin{array}{lllllllllll}6 & 23 & 85 & 1 & 2 & 7.28 & 5 & 13 & 06 & 24 & 08\end{array}$ $\begin{array}{lllllllllll}7 & 23 & 85 & 1 & 2 & 9.07 & 5 & 13 & 06 & 24 & 09\end{array}$

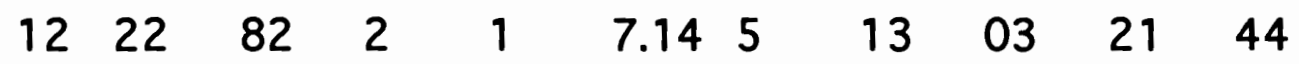
$\begin{array}{lllllllllll}19 & 32 & 85 & 2 & 4 & 6.98 & 5 & 11 & 04 & 20 & 88\end{array}$ $\begin{array}{lllllllllll}39 & 22 & 82 & 1 & 2 & 6.50 & 5 & 12 & 14 & 31 & 26\end{array}$ $\begin{array}{lllllllllll}41 & 21 & 80 & 1 & 2 & 7.82 & 5 & 13 & 13 & 31 & 35\end{array}$ $\begin{array}{lllllllllll}57 & 20 & 81 & 2 & 4 & 7.88 & 4 & 10 & 10 & 24 & 20\end{array}$

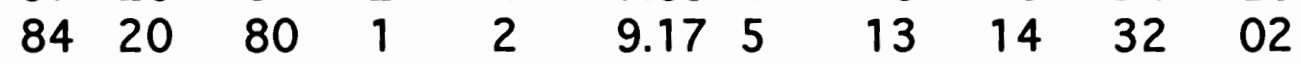
$\begin{array}{lllllllllll}85 & 28 & 82 & 1 & 3 & 7.28 & 5 & 12 & 03 & 20 & 19\end{array}$ $\begin{array}{lllllllllll}86 & 20 & 85 & 1 & 2 & 7.02 & 5 & 12 & 09 & 26 & 64\end{array}$

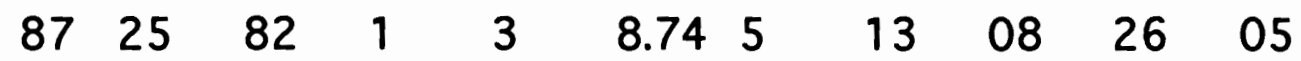
$\begin{array}{lllllllllll}92 & 33 & 83 & 1 & 3 & 8.32 & 5 & 12 & 04 & 21 & 45\end{array}$ $\begin{array}{lllllllllll}97 & 22 & 81 & 1 & 2 & 6.72 & 5 & 10 & 00 & 15 & 12\end{array}$ $\begin{array}{lllllllllll}98 & 19 & 86 & 1 & 2 & 6.42 & 5 & 11 & 12 & 28 & 05\end{array}$ $\begin{array}{lllllllllll}101 & 25 & 81 & 2 & 4 & 6.85 & 5 & 12 & 14 & 31 & 51\end{array}$

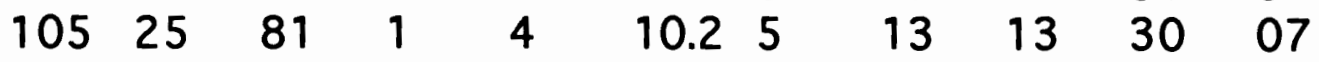

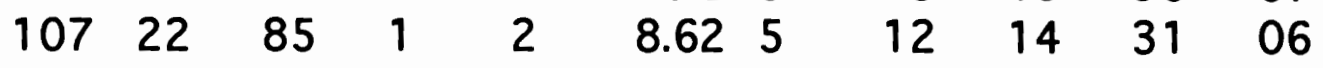
$\begin{array}{lllllllllll}109 & 21 & 85 & 1 & 3 & 6.34 & 5 & 12 & 09 & 26 & 25\end{array}$ $\begin{array}{lllllllllll}114 & 24 & 83 & 1 & 2 & 7.94 & 5 & 11 & 04 & 20 & 07\end{array}$ $\begin{array}{lllllllllll}119 & 26 & 91 & 1 & 2 & 7.92 & 5 & 12 & 02 & 19 & 02\end{array}$

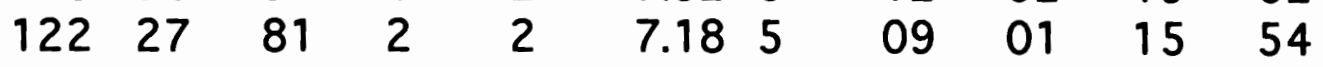
$\begin{array}{lllllllllll}142 & 22 & 82 & 2 & 1 & 6.66 & 5 & 11 & 04 & 20 & 05\end{array}$ 
Normal Group Statistics

\# CA/I CA/F SEX SES DSS PA1 PA2 PA3 PAT LDS

$\begin{array}{lllllllllll}4 & 23 & 84 & 1 & 3 & 6.60 & 5 & 11 & 00 & 16 & 93\end{array}$

$\begin{array}{lllllllllll}9 & 19 & 81 & 1 & 4 & 9.06 & 4 & 08 & 07 & 19 & 14\end{array}$

$\begin{array}{lllllllllll}14 & 25 & 85 & 1 & 1 & 7.82 & 5 & 12 & 02 & 19 & 211\end{array}$

$\begin{array}{lllllllllll}27 & 22 & 86 & 1 & 4 & 6.52 & 5 & 10 & 13 & 28 & 146\end{array}$

$\begin{array}{lllllllllll}40 & 25 & 84 & 2 & 4 & 8.82 & 5 & 11 & 14 & 30 & 213\end{array}$

$\begin{array}{lllllllllll}50 & 24 & 83 & 1 & 1 & 8.16 & 5 & 12 & 14 & 31 & 203\end{array}$

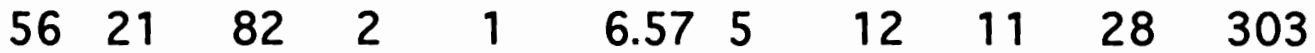

$\begin{array}{lllllllllll}58 & 34 & 92 & 1 & 1 & 10.8 & 5 & 11 & 14 & 30 & 263\end{array}$

$\begin{array}{lllllllllll}59 & 34 & 91 & 2 & 1 & 9.35 & 5 & 13 & 12 & 30 & 263\end{array}$

$\begin{array}{lllllllllll}69 & 16 & 84 & 1 & 3 & 6.46 & 5 & 11 & 05 & 21 & 43\end{array}$

$\begin{array}{lllllllllll}72 & 20 & 82 & 1 & 4 & 7.46 & 5 & 12 & 13 & 30 & 145\end{array}$

$\begin{array}{lllllllllll}81 & 26 & 83 & 2 & 5 & 8.42 & 5 & 12 & 13 & 30 & 279\end{array}$

$\begin{array}{llllllllll}95 & 19 & 85 & 1 & 6.38 & 4 & 10 & 01 & 15 & 11\end{array}$

$\begin{array}{lllllllllll}113 & 26 & 84 & 2 & 3 & 9.28 & 5 & 12 & 12 & 29 & 257\end{array}$

$\begin{array}{lllllllllll}126 & 29 & 90 & 2 & 1 & 6.68 & 5 & 13 & 12 & 30 & 264\end{array}$

$\begin{array}{lllllllllll}129 & 33 & 87 & 1 & 5 & 7.96 & 5 & 12 & 13 & 30 & 275\end{array}$

$\begin{array}{lllllllllll}130 & 29 & 82 & 1 & 3 & 6.88 & 5 & 12 & 14 & 31 & 222\end{array}$

$\begin{array}{lllllllllll}131 & 31 & 84 & 1 & 2 & 7.44 & 5 & 12 & 10 & 27 & 257\end{array}$

$\begin{array}{lllllllllll}132 & 20 & 85 & 1 & 1 & 8.04 & 5 & 12 & 12 & 29 & 102\end{array}$

$\begin{array}{lllllllllll}133 & 27 & 87 & 1 & 4 & 8.68 & 5 & 12 & 13 & 30 & 269\end{array}$

$\begin{array}{lllllllllll}139 & 29 & 84 & 2 & 2 & 10.8 & 5 & 13 & 14 & 32 & 274\end{array}$

$\begin{array}{lllllllllll}141 & 22 & 84 & 1 & 1 & 8.92 & 5 & 13 & 05 & 23 & 173\end{array}$

$\begin{array}{lllllllllll}144 & 24 & 85 & 1 & 4 & 9.18 & 5 & 10 & 14 & 29 & 197\end{array}$

$\begin{array}{lllllllllll}150 & 28 & 82 & 2 & 1 & 6.78 & 5 & 13 & 13 & 31 & 281\end{array}$

\section{ELD GROUP STATISTICS}

\# CA/I CA/F SEX SES DSS PA1 PA2 PA3 PAT LDS

$\begin{array}{lllllllllll}15 & 32 & 87 & 1 & 3 & 5.23 & 3 & 06 & 13 & 22 & 84\end{array}$

$\begin{array}{lllllllllll}26 & 31 & 86 & 1 & 3 & 6.05 & 4 & 09 & 01 & 14 & 72\end{array}$

$\begin{array}{lllllllllll}29 & 26 & 85 & 2 & 5 & 5.38 & 5 & 06 & 00 & 11 & 14\end{array}$

$\begin{array}{lllllllllll}93 & 24 & 82 & 1 & 3 & 4.54 & 5 & 12 & 14 & 31 & 22\end{array}$

$\begin{array}{lllllllllll}94 & 31 & 87 & 1 & 3 & 5.00 & 5 & 13 & 14 & 32 & 23\end{array}$

$\begin{array}{lllllllllll}100 & 29 & 84 & 1 & 1 & 6.26 & 5 & 12 & 14 & 31 & 27\end{array}$

$\begin{array}{lllllllllll}111 & 25 & 80 & 2 & 3 & 7.02 & 5 & 12 & 07 & 24 & 13\end{array}$ 